\title{
O JOGO DE TABULEIRO NO CONTEXTO DA EDUCAÇÃO LIBERTADORA E DO ENSINO POR COMPETÊNCIA
}

\section{THE BOARD GAME IN THE CONTEXT OF RELEASING EDUCATION AND TEACHING BY COMPETENCE}

\author{
Laura Dourado Loula Regis*
}

\begin{abstract}
Resumo: O presente trabalho tem como objetivo descrever a experiência de implementação do jogo de tabuleiro em dois componentes curriculares de sintaxe, no curso de Letras. Teoricamente fundamentados pela Teoria da Ação Dialógica (FREIRE, 1992, 1996) e pela proposta de ensino por competência (ALLAL, 2004), apresentamos as metodologias ativas (FILATRO; CAVALCANTI, 2018) e, em específico, o jogo de tabuleiro como uma alternativa de desenvolvimento das competências e habilidades cognitivas e socioemocionais no contexto de uma sequência de atividades. Norteados por uma filosofia de educação que se pretende libertadora, os resultados da experiência apontam para a possibilidade de sistematização dos objetos de aprendizagem do domínio cognitivo; a construção dialética "teoria-prática" e "professor-aluno" no contexto da sequência de atividades; o potencial exploratório das competências e habilidades cognitivas e socioemocionais; o favorecimento da autonomia do aluno.
\end{abstract}

Palavras-chave: Jogo de tabuleiro. Metodologias ativas. Ensino superior.

Abstract: The present work aims to describe the experience of implementing the board game in two curricular syntax components, in the Letters. Theoretically based on the Dialogic Action Theory (FREIRE, 1992; 1996) and the proposal for teaching by competence (ALLAL, 2004), we present the active methodologies (FILATRO, CAVALCANTI, 2018) and, specifically, the board game as an alternative development of cognitive and socioemotional skills and abilities, in the context of a sequence of activities. Guided by an educational philosophy that aims to be liberating, the results of the experience point to the possibility of systematizing the learning objects of the cognitive domain; the dialectical construction 'theory-practice' and 'teacher-student in the context of the sequence of activities; the exploratory potential of cognitive and socioemotional skills and abilities; favoring student autonomy.

Keywords: board game. active methodologies. university education.

\section{Introdução}

Embora o manuscrito Pedagogia do oprimido (FREIRE, 1992) tenha alcançado mais de meio século ${ }^{1}$ de vida, é inegável a atualidade da obra em virtude dos inexpressivos avanços em relação à superação da educação bancária, descrita pelo autor: o ato de "depositar", de transferir, de transmitir conhecimentos e valores é de responsabilidade do educador, cabendo aos educandos a posição passiva de receptáculo do "depósito".

A Teoria da Ação Dialógica (TAD), proposta por Paulo Freire nessa obra, supõe uma educação como prática libertadora, a partir da conscientização, do engajamento e da libertação, numa perspectiva dialógica entre os sujeitos envolvidos no processo educacional. Num âmbito mais geral, os princípios da TAD referem-se à "colaboração",

\footnotetext{
* Possui graduação em Letras pela Universidade Federal de Campina Grande (2004), mestrado em Linguagem e Ensino pela Universidade Federal de Campina Grande (2007) e doutorado pelo Programa de Pós-graduação em Linguística (PROLING). É professora adjunta na Unidade Acadêmica de Letras da Universidade Federal de Campina Grande (UFCG) e coordenadora do Projeto de Pesquisa (Re)significação da prática docente a partir das metodologias ativas, com ênfase no desenvolvimento de novas práticas metodológicas de aprendizagem. E-mail: douradoloula@ gmail.com

${ }^{1}$ Estamos considerando o ano de conclusão do manuscrito - 1968 -, quando Paulo Freire vivia o desterro em Santiago, no Chile.
} 
união, organização e síntese cultural. Resguardadas as devidas particularidades, os princípios da TAD seriam transpostos ao campo educacional, viabilizados pela dialogicidade entre os sujeitos envolvidos no processo.

A construção dessa dialogicidade, essência da educação como prática libertadora por seu caráter pedagógico e genuinamente democrático na revolução, vai requerer, no entanto, o deslocamento do educando de uma posição passiva para um lugar ativo: um sujeito histórico socialmente, estruturante do processo educativo. Um "co-laborador" na dialética "educador-educando", cuja autonomia constitui fator fundamental no processo de aprendizagem (FREIRE, 1996).

Acreditamos que um modo exequível da educação como prática libertadora parece corresponder à proposta de ensino por competência (ALLAL, 2004), desde que não se perca de vista o forte viés humanista da filosofia freireana. Grosso modo, essa proposta defende o desenvolvimento dos componentes cognitivos, afetivos, sociais e sensório-motores do aprendiz em ambiente escolar. O desenvolvimento dessa simbiose de aprendizagens pressupõe, entretanto, um saber que se constrói coletivamente em espaços coletivos de reflexão.

Em atendimento à prerrogativa da pedagogia freireana e da educação orientada por competência, as metodologias ativas se apresentam de forma oportuna, na medida em que possuem o viés humanista e recuperam as matrizes conceituais dessas contribuições, transferindo o foco do ensino para a aprendizagem. Mais que promover a autonomia ao aluno, as metodologias ativas "dão ênfase ao papel protagonista do aluno, ao seu envolvimento direto, participativo e reflexivo em todas as etapas do processo, experimentando, desenhando, criando, com orientação do professor (...)" (BACICH; MORAN, 2018, p. 4).

Com as potencialidades características das metodologias ativas, o jogo de tabuleiro (em grupo) se apresenta como uma estratégia produtiva de desenvolvimento simultâneo das competências e habilidades ${ }^{2}$ cognitivas, afetivas, sociais e sensóriomotoras. Desse modo, o objetivo deste trabalho reside em descrever a experiência de implementação do jogo de tabuleiro no ensino superior, em dois componentes curriculares de sintaxe do curso de Letras da Universidade Federal de Campina Grande.

O trabalho está organizado em duas seções, além desta introdução: breve apresentação dos conceitos teórico-metodológicos estruturantes do trabalho: dialética do conhecimento (FREIRE, 1992, 1996); ensino por competência (ALLAL, 2004); metodologias ativas; e uma seção de descrição da experiência, com apresentação do contexto de implementação do jogo, o processo de elaboração das cartas e os objetos de aprendizagem e componentes contemplados. Como metodologias ativas, estamos considerando "as estratégias, técnicas, abordagens e perspectivas de aprendizagem individual e colaborativa que envolvem e engajam os estudantes no desenvolvimento de projetos e/ou atividades práticas" (FILATRO; CAVALCANTI, 2018).

Entre as diversas metodologias ativas, a seleção do jogo se justifica por este apresentar um potencial significativo de desenvolvimento das competências e habilidades para além do componente cognitivo, sendo este histórico e quase exclusivamente privilegiado no modelo tradicional de educação. No contexto de implementação do jogo, pela própria natureza do trabalho colaborativo, competências e habilidades relacionadas aos componentes afetivos, sociais e sensório-motores são exigidas do aprendiz.

2 Compreendemos competência como "saber fazer algo" e habilidade como aptidão, destreza e/ou disposição, necessária(s) a esse "saber fazer". 
Compreendemos a relevância de discussões como esta, que enfocam a correlação entre os conhecimentos acumulados na formação inicial, na experiência docente e as demandas de novas metodologias de ensino adequadas a uma educação libertadora orientada por competência. Como uma forma de enfrentamento dessa questão, esta proposta representa a criação de um espaço para discussão e possível resolução de problemas que vão emergir durante as etapas de discussão teórica, produção de material didático de apoio e implementação de novas metodologias.

\section{A pedagogia libertadora e o ensino por competência: complementaridades}

A teoria dialética do conhecimento de Paulo Freire é considerada por Gadotti (2001) como uma das grandes contribuições para o pensamento pedagógico brasileiro no século XX. Para Freire (1992):

[...] se os homens são seres do quefazer é exatamente porque seu fazer é ação e reflexão. É práxis. É transformação do mundo. E, na razão mesma em que o quefazer é práxis, todo fazer do quefazer tem de ter uma teoria que necessariamente o ilumine. O quefazer é uma teoria e prática. É reflexão e ação. Não pode reduzir-se, [...], ao tratarmos a palavra, nem ao verbalismo, nem ao ativismo. (p. 145).

Intrínseca à retroalimentação entre teoria e prática, figura a "ação-reflexão": a melhor maneira de refletir seria, portanto, pensar a prática e retornar a ela para transformá-la. No entanto, a dialética se presentifica não apenas na relação entre teoria e prática, mas na relação dinâmica de aprendizagem entre educador e educando "educador-educando e educandos-educadores". Para isso, o educando precisa ser deslocado da posição passiva da educação bancária para uma posição ativa de "colaborador" no processo de aprendizagem.

$\mathrm{Na}$ troca de saberes entre o educador e os educandos, estes constroem e reconstroem seus saberes desenvolvendo sua autonomia. Assim, "[...] nas condições de verdadeira aprendizagem", Freire (1996) afirma que "os educandos vão se transformando em reais sujeitos da construção e da reconstrução do saber ensinado, ao lado do educador, igualmente sujeito do processo" (FREIRE, 1996, p. 26). A construção da autonomia se centraria na vivência de experiências estimuladoras advindas da tomada de decisão e da possibilidade de o aluno assumir responsabilidade por sua própria aprendizagem.

De modo convergente e complementar à proposta freireana, julgamos estar a proposta de aquisição das competências em situação escolar apresentada por Allal (2004). A autora define competência como "uma rede integrada e funcional constituída por componentes cognitivos, afetivos, sociais, sensório-motores, capaz de ser mobilizada em ações finalizadas diante de uma família de situações” (p. 83).

Respaldada pela ideia-chave de Dewey (1938/1963), de que a forma como o indivíduo aprende faz parte daquilo que ele aprende, Allal (2004, p. 83) advoga que "uma competência sempre se constrói por meio de uma aprendizagem na 'prática', o que implica a apropriação, não só de saberes e savoir-faire, mas também de modos de interação e de ferramentas valorizadas no contexto em questão".

Como não é apresentado em Allal (2004) em modelo didático acabado para desenvolvimento das competências dos diversos componentes, recuperamos aqui a Taxonomia de Bloom, um esquema genérico das etapas de planificação e avaliação da 
aprendizagem. As categorias propostas nesse modelo dividem-se em: cognitivo, afetivo e psicomotor. O domínio cognitivo está relacionado à obtenção de novos conhecimentos e ao desenvolvimento intelectual, de habilidades e competências; o domínio afetivo refere-se ao desenvolvimento da postura emocional e comportamental do indivíduo diante de diferentes situações; e o domínio psicomotor, ao desenvolvimento de habilidades físicas (BLOOM et al., 1973).

A Taxonomia de Bloom classifica em níveis os objetivos de aprendizagem do aluno, e é preciso que o aluno adquira habilidades e competências em um nível para que esteja apto a compreender o seguinte, portanto as etapas são evolutivas. A Fig. 1, a seguir, é representativa dos níveis e objetivos de aprendizagem do domínio cognitivo, na versão já revisada da Taxonomia.

Figura 1 - Taxonomia de Bloom (revisada)

\section{TAXONOMIA DE BLOOM REVISADA}

\section{COMPLEXIDADE}

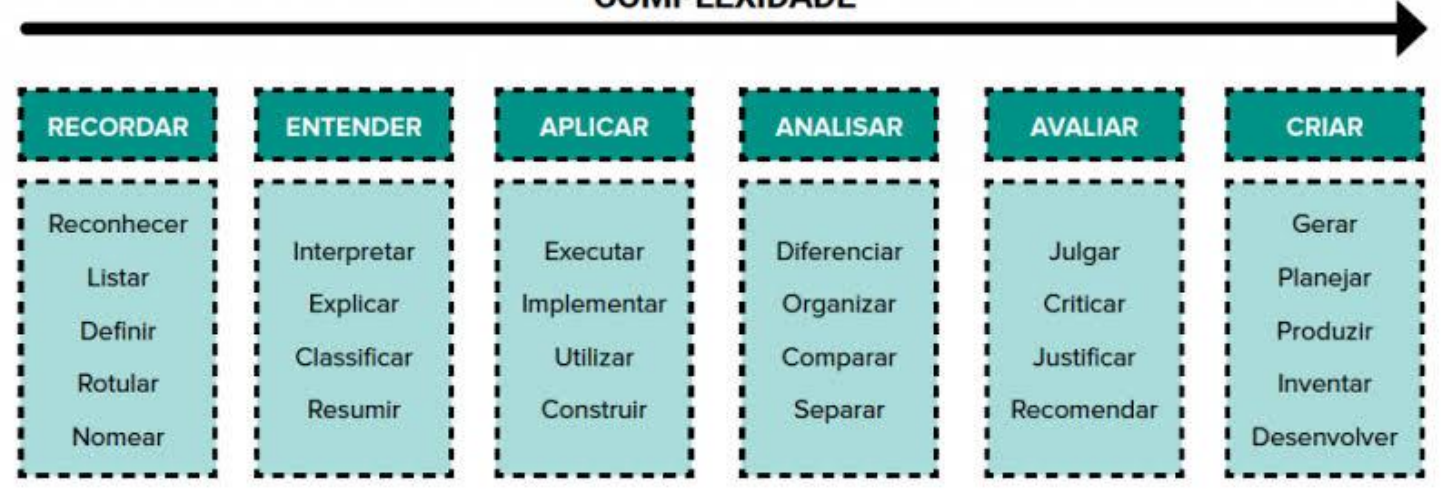

Fonte $^{3}:$ https://www.tuneduc.com.br/trabalhando-habilidades-do-enem/

O domínio cognitivo da estrutura encontra-se dividido em subcategorias, que são: Recordar, relacionado a lembrar-se do que aprendeu quando necessário, ou seja, é a capacidade de armazenar as informações e trazê-las à tona no momento oportuno; Entender consiste em dar sentido ao conteúdo de forma que seja possível seu entendimento e reprodução; Aplicar refere-se à habilidade de utilizar o conhecimento adquirido para a resolução de problemas práticos e em novas situações; Analisar compreende a capacidade de fragmentar o conteúdo em partes menores para compreensão da estrutura final. O aluno precisa ser capaz de identificar as partes separadamente, comparando-as e identificando seus relacionamentos e seus princípios de organização na criação da estrutura completa; Avaliar é justamente a habilidade adquirida em fazer julgamentos de valor, ou seja, conseguir avaliar uma situação, um projeto, uma proposta com base em critérios internos ou externos para um fim específico; e, por último, a subcategoria Criar, que está relacionada à habilidade de acrescentar e unir partes na construção de uma nova estrutura, bem como relacionar partes não organizadas para formar uma nova proposta (KRATHWOHL, 2002).

Faz-se oportuno ressaltar, no entanto, que a Fig. 1 refere-se, especificamente, ao domínio cognitivo e, na proposta de um ensino orientado por competência, os atributos afetivos, sociais e sensório-motores, em Alall (2004), ou afetivos e

${ }^{3}$ Acesso em: 28 de fev. de 2020. 
psicomotores, em Bloom (1973), precisam ser desenvolvidos, mobilizados e avaliados simultaneamente aos do domínio cognitivo.

Há, pois, no esteio do desenvolvimento dessas aprendizagens um processo inextricável de incorporação das metodologias ativas, que orientam a realização de atividades práticas e aplicadas, o trabalho colaborativo (em pares ou em grupos) e, desse modo, tornam visíveis não apenas as competências e habilidades cognitivas, mas, principalmente, as socioemocionais.

Correspondem então às transversalidades das metodologias ativas: experiência, autonomia, dialogia, diversidade, acesso às emoções, aprendizagem, interdisciplinaridade, transdisciplinaridade, transprofissionalidade, desenvolvimento humano e social sustentável. Tudo isso somado ao deslocamento do aluno de um lugar passivo, no modelo tradicional, para o papel de protagonista da própria aprendizagem. Passamos a discutir mais detidamente a proposta das metodologias ativas a seguir.

\subsection{As metodologias ativas como alternativa de operacionalização da educação libertadora orientada por competência}

Aparentemente, um princípio que permeia a proposta das metodologias ativas e subjaz a todo e qualquer método, refere-se ao conceito de sala de aula invertida. $\mathrm{O}$ conceito básico de inversão se justifica, portanto, por se realizar em casa o que era feito em aula, por exemplo: assistir a palestras e, em aula, o trabalho que era feito em casa, como resolver problemas (BERGMANN; SAMS, 2012). A Fig. 2 representa o esquema básico de uma sala de aula invertida e suas respectivas etapas: antes, durante e depois da aula.

Figura 2 - Representação da sala de aula invertida

\section{SALA DE AULA INVERTIDA}

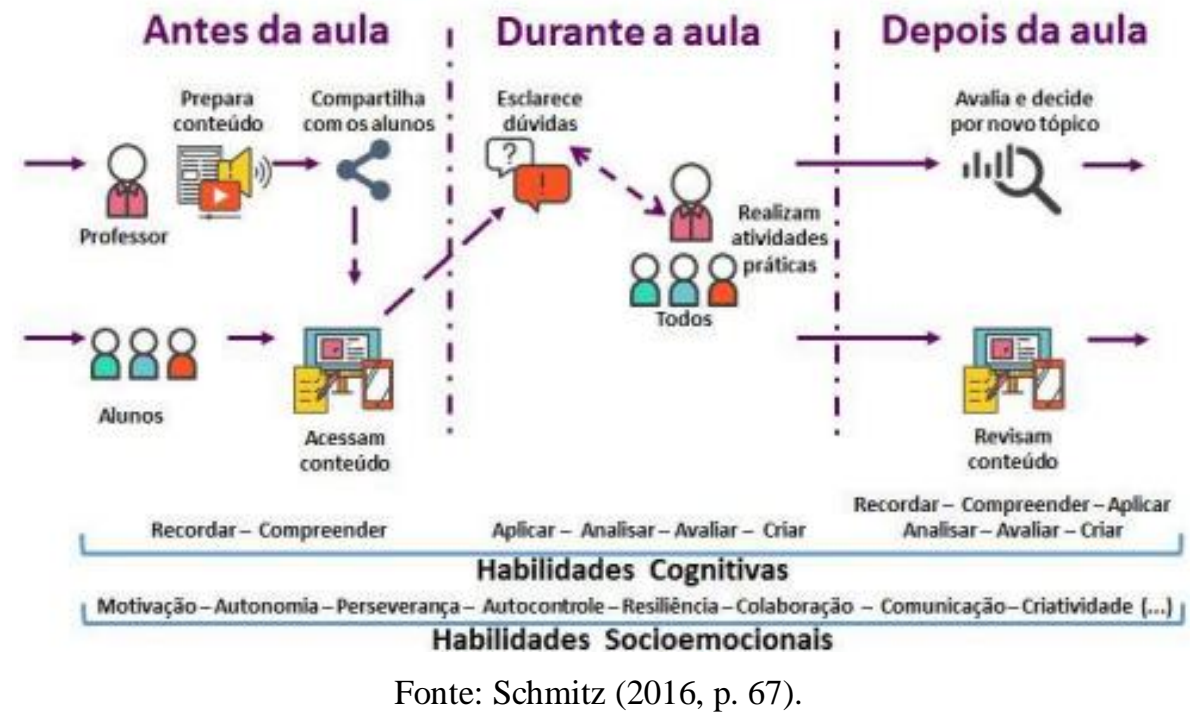

Em nosso ambiente acadêmico, a "sala de aula invertida" se realiza, de modo muito elementar, quando os professores solicitam que os alunos leiam em casa textos teóricos ou façam pesquisas prévias e, em sala, realizam discussões e/ou propõem aplicações práticas acerca de determinado tópico. A diferença entre esse "modelo acadêmico elementar" e a sala de aula invertida, representada na Fig. 2, reside apenas 
no modo de compartilhamento das leituras prévias, feitas em plataformas digitais, bem como na diversidade multimodal desses textos: videoaulas, infográficos, podcasts, hipertextos, etc.

É interessante ainda destacar, na Fig. 2, que Schmitz (2016) prevê, nesse movimento de inversão da aula, a possibilidade não apenas do desenvolvimento das habilidades cognitivas, mas também das socioemocionais, ${ }^{4}$ relativas a comportamentos, atitudes e características de personalidade - autocontrole, resiliência, colaboração, etc., não diretamente ligadas ao domínio das disciplinas escolares. Rodrigues (2015) atenta para o fato de que especialistas nas áreas de educação, psicologia e economia:

Têm defendido que o desenvolvimento das competências e habilidades socioemocionais/não cognitivas (...) seria tão ou mais importante para promover o sucesso individual dos estudantes do que as próprias competências e habilidades cognitivas. (p. 3-4).

Nesse contexto, as metodologias ativas ganham relevância por quase sempre promoverem atividades práticas, em pares ou em grupos. É apenas na prática coletiva que habilidades socioemocionais como colaboração, respeito e ética podem ser verificadas para além do discurso. Em outras palavras, no modelo convencional de aula expositiva e de atividades individuais, possivelmente a única fonte de dados sobre o quanto o sujeito é colaborativo, respeitoso e ético seja o seu próprio discurso. Na prática, com a interação e todas as suas imprevisibilidades, o comportamento desse sujeito pode destoar completamente do seu discurso.

Para potencializar o desenvolvimento das competências e habilidades (cognitivas e socioemocionais), são sugeridos diversos métodos ativos, articulados às novas tecnologias, como plataformas digitais e aplicativos. A relação entre "sala de aula invertida", métodos disponíveis e tecnologias está representada na Fig. 3:

Figura 3 - Integração sala de aula invertida, metodologias e tecnologias

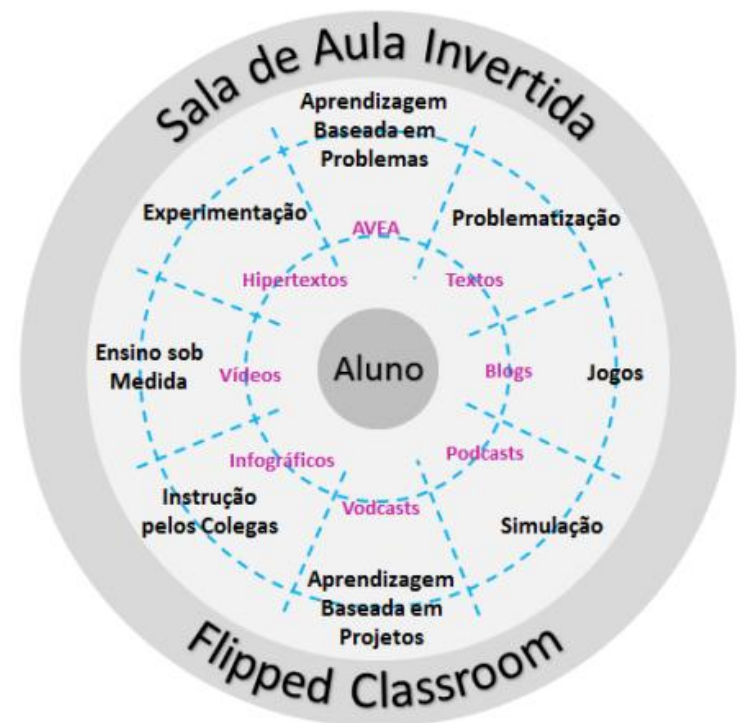

Fonte: Schmitz (2016, p. 78).

\footnotetext{
${ }^{4}$ As habilidades socioemocionais de Schmitz (2016) parecem corresponder aos componentes afetivo psicomotor da Taxonomia de Bloom.
} 
Ao conceito geral de "sala de aula invertida", conectam-se os métodos (jogos, problematização ou aprendizagem baseada em problemas, instrução pelos colegas, etc.) e as ferramentas potencializadoras dessa proposta (blogs, vídeos, Ambiente Virtual de Ensino e Aprendizagem - AVEA, etc.).

Nesse cenário, a figura do professor, em sala, passa de "detentor absoluto do saber" a de um colaborador, um orientador, imprescindível e fundamental ao processo de ensino-aprendizagem. Em todas as etapas do planejamento (elaboração, execução e aperfeiçoamento), o professor continua a assumir as mesmas responsabilidades determinação dos objetivos, seleção e organização dos conteúdos, seleção e organização dos procedimentos de ensino, seleção de recursos, seleção de procedimentos de avaliação e estruturação do plano de avaliação, execução do plano, avaliação, feedback e replanejamento -, com a diferença de que, durante a etapa de execução do plano, sua mediação será decisiva na promoção da autonomia do aluno, da afetividade e do trabalho colaborativo.

No hall das metodologias ativas, o jogo, enquanto procedimento metodológico, garante os benefícios característicos dessas metodologias e, de modo particular, reconfigura os papéis do aluno e do professor em sala de aula. Para Antunes (2014, p. 36), o jogo ajuda o aluno "a construir suas novas descobertas, desenvolve e enriquece sua personalidade e simboliza um instrumento pedagógico que leva ao professor a condição de condutor, estimulador e avaliador da aprendizagem". E, uma vez aprimorados os processos de socialização, haveria uma implicação positiva em termos de cidadania, em virtude, principalmente, da evidência e do trabalho atento às habilidades socioemocionais.

Há que se ponderar, no entanto, que o jogo não se restrinja apenas à garantia de ludicidade e dinamismo nas aulas ou que se resuma a um mero recurso para execução de velhas práticas.

Em geral, o elemento que separa um jogo pedagógico de um outro de caráter apenas lúdico é que os jogos ou brinquedos pedagógicos são desenvolvidos com a intenção explícita de provocar uma aprendizagem significativa, estimular a construção de um novo conhecimento e, principalmente, despertar o desenvolvimento de uma habilidade operatória. (ANTUNES, 2014, p. 38).

Ao contrário do que muitos podem ser levados a pensar, o jogo não se constitui mera "brincadeira" em sala de aula, não se configura uma ação improvisada, sem planejamento prévio, nem muito mesmo desabona o trabalho com os objetos de aprendizagem relacionados ao domínio cognitivo. Ao contrário disso, a construção de um jogo pedagógico exige do professor o cumprimento de todas as etapas do planejamento e mais: vai exigir do professor o processo de didatização dos objetos de aprendizagem. $\mathrm{Na}$ elaboração de perguntas para um jogo, por exemplo, o professor precisará transpor um conceito teórico, abstrato, para uma forma aplicada. E essa não é uma tarefa fácil! Do aluno, o jogo pedagógico vai exigir, para além das habilidades cognitivas, as habilidades socioemocionais na interação.

Por fim, vale destacar o caráter afetivo que envolve o jogo e as potencialidades do lúdico. Enquanto ferramenta metodológica, a ludicidade apresenta-se de forma imprescindível ao melhor desempenho dos educadores em sua ação pedagógica.

A ludicidade é uma necessidade do ser humano em qualquer idade e não pode ser vista apenas como diversão. $O$ desenvolvimento do 
aspecto lúdico facilita a aprendizagem, o desenvolvimento pessoal, social e cultural, colabora para uma boa saúde mental, prepara para um estado interior fértil, facilita os processos de socialização, comunicação, expressão e construção do conhecimento. (SANTOS, 2007, p. 12).

Às potencialidades do lúdico, há que se articular as contribuições inerentes às metodologias ativas: coletividade, atividades práticas, socialização, protagonismo do aluno, desenvolvimento das habilidades cognitivas e socioemocionais, etc. No tópico a seguir, passamos a descrever os resultados dessa articulação em nossa experiência de intervenção.

\section{0 contexto geral da intervenção}

Em atendimento às prerrogativas de uma educação libertadora orientada por competência, as metodologias ativas foram progressivamente incorporadas aos componentes curriculares sob nossa responsabilidade: Sintaxe Oracional e Sintaxe Interoracional. Nas duas turmas, a média de alunos matriculados ficava em torno de 25 alunos, o que tornava possível a adoção das metodologias ativas. A sua implementação mostrou-se oportuna, principalmente, na construção da dialética "teoria-prática", "professor-aluno"; no potencial exploratório das competências e habilidades cognitivas e socioemocionais; bem como no favorecimento da autonomia do aluno ao longo das sequências de atividades nos referidos componentes curriculares.

De modo geral, as metodologias ativas não apenas figuraram nas etapas de planejamento com o propósito de retroalimentação teoria-prática, mas também na composição das etapas da avaliação processual - pesquisa, autoavaliação e avaliação colaborativa, etc. -, e ainda na garantia da dialética professor-aluno em momentos de aula, com "rotação por estações", jogos e Team-based Learning (Aprendizagem Baseada em Equipes/Times). A Fig. 4 representa graficamente, a título de ilustração, algumas das metodologias ativas implementadas ao longo dos três estágios constitutivos dos componentes curriculares.

Figura 4: Representação esquemática da sequência de atividades desenvolvidas nos componentes Sintaxe Oracional e Interoracional

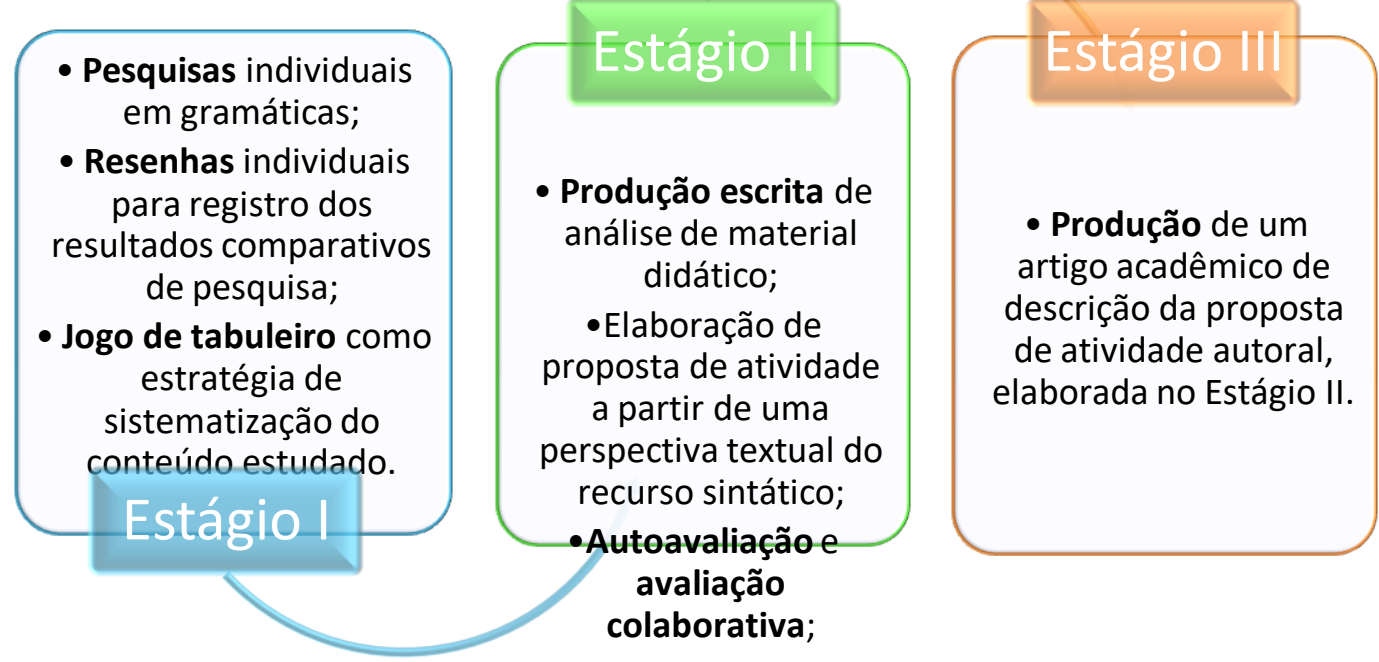

Fonte: Elaborado pela autora. 
No Estágio I, a metodologia ativa "pesquisa", definida como primeira atividade avaliativa e realizada individualmente, teve como propósito o (re)conhecimento dos objetos de aprendizagem em seus respectivos componentes curriculares - por exemplo, sujeito e predicado em Sintaxe Oracional e coordenação e subordinação em Sintaxe Interoracional. Em outras palavras, pretendia-se o (re)conhecimento dos objetos de aprendizagem pelos alunos, respeitando seu tempo e modos de aprendizagem, não eliminando, inclusive, um possível retorno à descrição morfológica. Os resultados das pesquisas foram registrados, comparativamente, por escrito, em formato de resenha crítica, no intuito de também avaliar as habilidades de compreensão, comparação, síntese e da própria produção escrita, típicas do componente cognitivo. Para além dessas habilidades, pretendia-se a promoção da autonomia do aluno, combinada com outras, como a gestão de tempo, categorizadas no domínio afetivo, na Taxonomia de Bloom, e como socioemocionais, por Schmitz (2016). Ainda no Estágio I, a metodologia ativa jogo de tabuleiro foi implementada como estratégia de sistematização do conteúdo estudado até o momento do jogo, no entanto, a descrição pormenorizada dessa implementação será realizada na sequência por se constituir o foco principal deste trabalho.

No Estágio II, foram propostas as atividades escritas individuais de análise de material didático e a elaboração de uma proposta de atividade autoral, com foco na exploração textual de um dos recursos sintáticos já revisados no Estágio I. Como apresentação dos resultados de ambas as atividades, a priori, foi pensada a forma de seminários individuais. Em um dos componentes curriculares, embora a orientação fosse de um tempo máximo de quinze minutos por apresentação, algumas acabaram extrapolando em muito esse limite e os seminários apenas referentes à primeira atividade - análise de material didático - acabaram se estendendo por três encontros, num total de seis aulas. Nitidamente, o formato repetitivo das apresentações tornou-se enfadonho e pouco produtivo, fator decisivo para a reconfiguração da socialização da segunda atividade - proposta de atividade autoral. A partir da sugestão dos próprios alunos, definimos a socialização em forma de círculo de discussão, com a realização de autoavaliação e avaliação colaborativa, com as contribuições orais da professora e dos colegas. É válido destacar nessa narrativa a presença da dialética "teoria-prática" e "professor-aluno". A dialética "teoria-prática" se presentificou na medida em que os alunos analisaram na prática, ou seja, no material didático, os objetos de aprendizagem estudados teoricamente nas gramáticas no Estágio I; já a dialética "professor-aluno" se concretizou na reconfiguração da socialização da segunda atividade em virtude da sugestão dada pelos próprios alunos.

Ademais, oportunamente, há que se destacar a autonomia alcançada pelos alunos em diversos momentos da sequência de atividades do Estágio II: na elaboração de análise de material didático e de uma proposta de atividade autoral, sem desconsiderar o desafiador e complexo processo de didatização dos recursos sintáticos; na sugestão de reconfiguração de uma atividade previamente definida pela professora; na postura assumida na autoavaliação e avaliação colaborativa, com colaborações e contribuições respeitosas e produtivas às atividades dos colegas.

No Estágio III, por fim, a elaboração de um artigo acadêmico de análise da proposta autoral - Writing Across the Curriculum (escrita por meio das disciplinas) promoveu o fechamento do processo avaliativo do componente curricular, sistematizando os saberes acumulados no Estágio I, com as atividades de pesquisa em gramáticas, e no Estágio II, com o movimento de análise de material didático e a elaboração da proposta de atividade autoral. 


\subsection{A execução do jogo de tabuleiro}

O jogo de tabuleiro foi incorporado nos dois componentes curriculares como um procedimento metodológico capaz de mobilizar as habilidades cognitivas e socioemocionais, definidas por Schmitz (2016), e as relativas aos domínios cognitivo, afetivo e psicomotor, da Taxonomia de Bloom. Por uma questão de recursividade, foi adotado um tabuleiro genérico, composto apenas por "casas", "partida" e "chegada", garantindo assim a sua retroalimentação em novos contextos de uso, conforme se apresenta na Fig. 5.

Figura 5 - Tabuleiro usado nas aulas

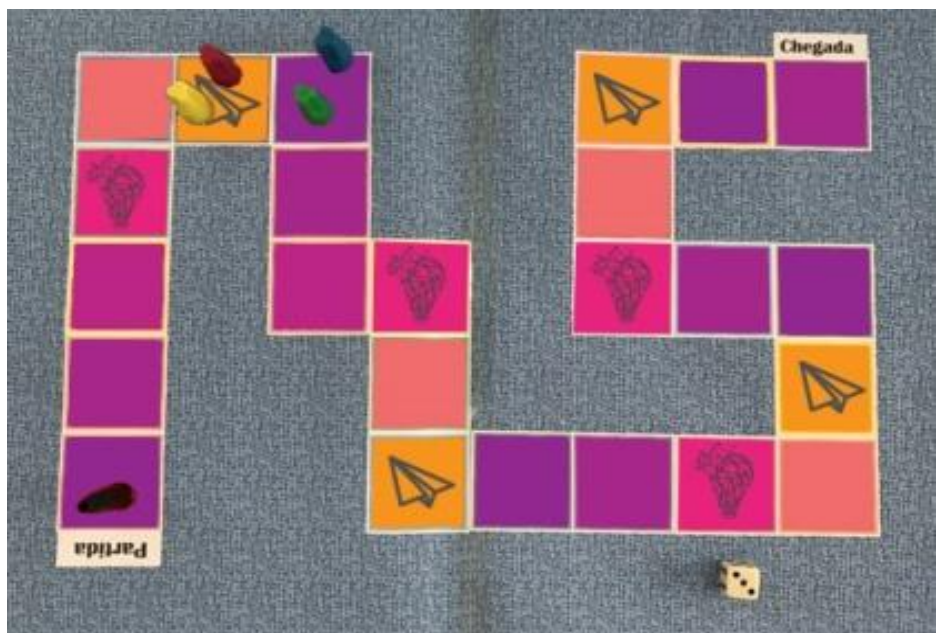

Fonte: Acervo pessoal.

A dinâmica do jogo foi a mesma nos dois componentes curriculares: depois de decidir "nos dados" ou no "par ou ímpar" qual grupo começaria, um integrante escolhia uma carta e lia duas vezes em voz alta para que todos ouvissem. A partir desse momento, um cronômetro com o tempo de um minuto e meio era acionado e, uma vez finalizado, o grupo tinha a opção de responder à pergunta ou passá-la para o segundo grupo e, caso este não respondesse, repassaria para o terceiro grupo, que, obrigatoriamente, responderia.

Antes de procedermos à descrição específica das competências e habilidades requeridas na implementação do jogo, destacamos a produtividade do jogo quanto à dialética "teoria-prática" e "professor-aluno", dentro do panorama geral dos componentes curriculares. Conforme informado acima, no Estágio I, uma das etapas da avaliação referia-se à pesquisa individual em quatro gramáticas e, como forma de registro dos resultados de pesquisa, à produção individual de uma resenha crítica comparativa pelos alunos. Desse modo, o jogo foi utilizado não apenas como sistematização do conteúdo, mas também como a realização da contraparte prática do par "teoria-prática", com o propósito de diagnosticar o desempenho dos alunos e redirecionar o olhar à teoria. Acreditamos também que a pesquisa prévia à execução do jogo se mostrou decisiva para o desempenho satisfatório dos grupos no jogo. Não apenas garantimos a premissa da "sala de aula invertida", com estudo prévio do conteúdo pelos alunos, como nos valemos dos próprios trabalhos produzidos por eles para elaborar as cartas do jogo. Talvez por isso mesmo os alunos tenham adquirido confiança suficiente para sugerir que, no momento do jogo, em vez de a professora apresentar a resposta correta após o erro de um determinado grupo, o grupo adversário faria isso com o benefício de recuperar pontos referentes àquela carta, o que foi 
prontamente atendido. Em outras palavras, na dialética "professor-aluno", os alunos passaram a ocupar o papel tradicionalmente desempenhado pelo professor no momento do feedback.

\subsubsection{Exploração das competências e habilidades cognitivas}

A elaboração das cartas se deu a partir da Taxonomia de Bloom (revisada), com o propósito de contemplar níveis cognitivos distintos e progressivos. As Fig. 6, 7, 8 e 9 são representativas das cartas elaboradas para discussão dos resultados da pesquisa no componente Sintaxe Oracional, mais especificamente, para sistematização do conteúdo predicado.

Figuras 6, 7, 8 e 9 - Cartas de tabuleiro elaboradas para o componente Sintaxe Oracional

Figura 6

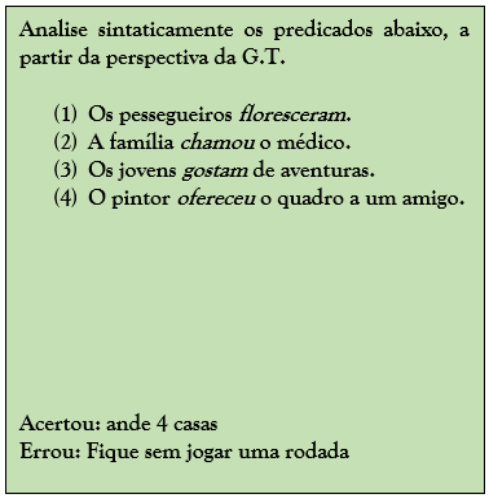

Figura 8

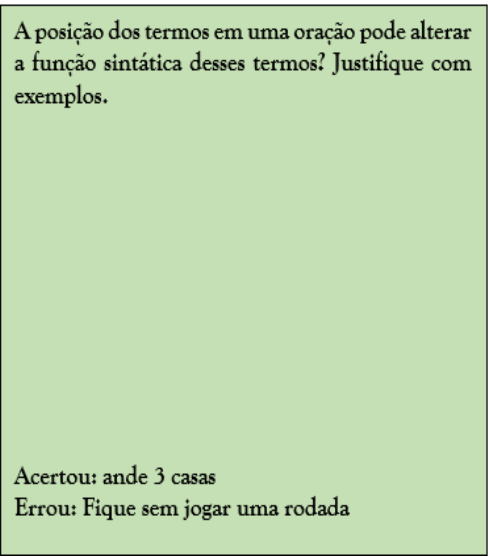

Figura 7

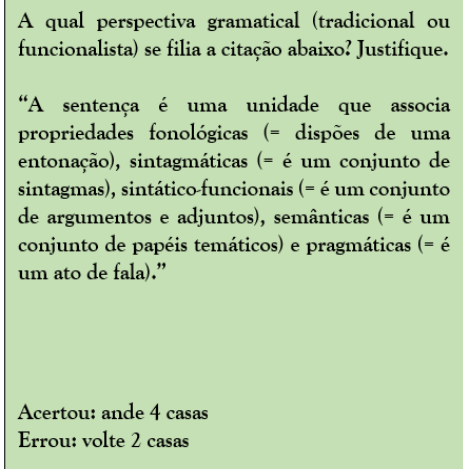

Figura 9

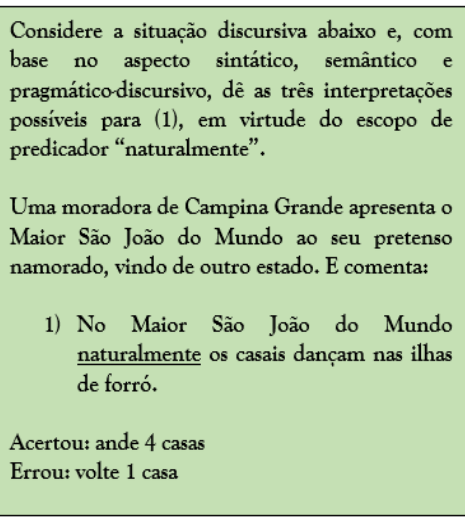

Considere a situação discursiva abaixo e, com base no aspecto sintático, semântico e pragmático-discursivo, dê as três interpretações possiveis para (1), em virtude do escopo de

Uma moradora de Campina Grande apresenta o Maior São João do Mundo ao seu pretenso

No Maior São João do Mundo naturalmente os casais dançam nas ilhas de forró

Fonte: Elaboração da autora

As cartas correspondentes às Fig. 6 e 7 foram elaboradas com o propósito de revisar o conteúdo predicado, numa perspectiva de revisão dos postulados da Gramática Tradicional (GT). De acordo com a Taxonomia de Bloom, para resolução de tais cartas, seriam exigidas as ações recordar, entender e aplicar, uma vez que, além da análise sintática requerida na Fig. 6, os alunos precisariam construir exemplos que justificassem a resposta à pergunta da Fig. 7.

Já as cartas correspondentes às Fig. 8 e 9 foram elaboradas com o intuito de promover a discussão da perspectiva gramatical mais próxima da vertente funcionalista, não contemplada no Ensino Médio, por se tratar de um aprofundamento teórico próprio 
do ensino superior. Na carta da Fig. 8, novamente, nos apropriamos de um trecho do trabalho escrito por um dos alunos para questionar a qual perspectiva se filiava tal citação. Além da identificação da filiação teórica, os alunos precisavam ainda justificar sua resposta.

A carta da Fig. 9, por fim, trazia não apenas o desafio da discussão de uma nova perspectiva teórica de gramática, mas ainda a propositura da análise sintática de um exemplo de uso real de língua, a partir dessa perspectiva. Ou seja, não se estava propondo a análise de exemplos clássicos da literatura, vistos e registrados pelos alunos em seus trabalhos, mas a de um "dado novo", um exemplo de uso real de língua.

De acordo com a Taxonomia de Bloom, para resolução das cartas correspondentes às Fig. 8 e 9, seriam exigidas as ações recordar, entender e analisar e avaliar, já que, para realizar a diferenciação justificada da filiação teórica, são pressupostos recordação e compreensão das respectivas correntes teóricas.

De modo similar à implementação do jogo de tabuleiro no componente curricular Sintaxe Oracional - pesquisa prévia nas gramáticas: "sala de aula invertida"; uso de trechos das resenhas dos alunos para elaboração das cartas -, deu-se a implementação no componente Sintaxe Interoracional, com a diferença de conteúdo conceitual (período composto por coordenação e por subordinação) e nível de complexidade exigida. As cartas das Fig. 10, 11 e 12 foram selecionadas como as representativas do maior nível de complexidade do jogo.

Figuras 10, 11 e 12 - Cartas de tabuleiro elaboradas para o componente Sintaxe Interoracional

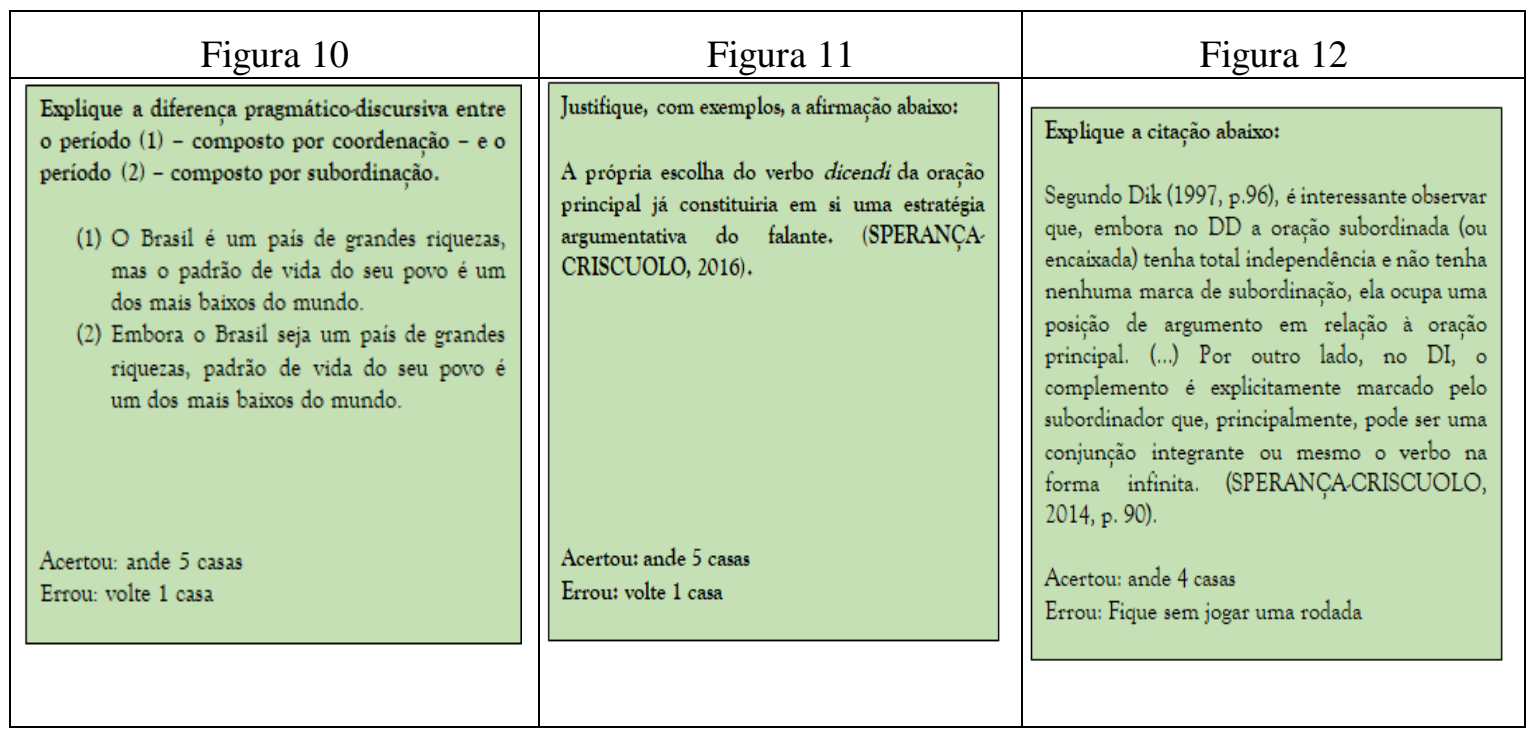

Fonte: A autora.

De modo geral, o maior grau de complexidade das cartas desse grupo se justifica por dois fatores: 1. aprofundamento de conteúdos específicos da vertente funcionalista da sintaxe; 2 mobilização todas as subcategorias do domínio cognitivo da Taxonomia de Bloom. Na Fig. 10, por exemplo, são exigidos conhecimentos relativos à análise sintática combinada aos aspectos pragmático-discursivos a partir de exemplos, e ainda ao conceito de evidencialidade, relacionado à arquitetura sintática: coordenação ou subordinação. Já na Fig. 11, é exigida uma compreensão mínima da defesa de alguns funcionalistas de que a própria seleção dos verbos dicendi já se constituiria uma estratégia argumentativa do falante. Ou seja, há que se ter uma compreensão textual/discursiva das escolhas gramaticais dentro do período sintático. Na Fig. 12, por 
fim, há um aprofundamento da abordagem textual/discursiva da sintaxe, na medida em que se explora a configuração morfossintática do período na inter-relação das orações subordinadas aos discursos diretos e indiretos. Em virtude do alto grau de complexidade exigido nessas operações, para resolução das questões correspondentes às Fig. 10, $11 \mathrm{e}$ 12, seriam exigidas todas as ações da Taxonomia: recordar, entender, aplicar, analisar, avaliar e criar.

É válido ressaltar ainda que, em ambos componentes curriculares, as cartas versavam desde a análise sintática numa perspectiva da GT - portanto, "metalinguagem" -, até a discussão de uma nova perspectiva teórica de gramática, com análise sintática e até mesmo elaboração de exemplos pelos próprios alunos, a partir dessa nova vertente - "epilinguagem". Em outras palavras, a elaboração das cartas de um jogo de tabuleiro pelo próprio professor possibilita a liberdade de exploração dos objetos de aprendizagem, mesmo os restritos ao domínio cognitivo, não apenas de forma mecânica e sistemática, mas também de forma reflexiva e criativa.

\subsubsection{Exploração das competências e habilidades socioemocionais}

Nesta experiência de intervenção, a personalização da aprendizagem da turma se deu por vários motivos: construção de um jogo exclusivo, elaborado especificamente para aquele momento e para aquela turma; utilização de trechos dos trabalhos dos alunos para elaboração das cartas do jogo, concedendo caráter legítimo de material didático às suas pesquisas e produções prévias; e reconhecimento ao esforço em uma atividade complexa ${ }^{5}$ de pesquisa. Acreditamos que essas ações, somadas à novidade de um jogo de tabuleiro no ensino superior, num componente curricular de descrição de língua, proporcionaram uma motivação geral perceptível em toda a turma.

De modo geral, julgamos a experiência satisfatória, em ambos componentes curriculares, tanto da perspectiva cognitiva - conforme descrição acima - quanto da socioemocional: os participantes demonstraram colaboração, respeito (às regras do jogo e aos colegas), criatividade, resiliência, motivação, ética, boa comunicação, etc., além da autonomia, demonstrada por uma das turmas ao sugerir que eles assumissem a responsabilidade do feedback durante o jogo.

No entanto, alguns alunos demonstraram insegurança em suas participações. Não foi e não seria possível precisar, porém, com apenas uma única execução do jogo, se tal insegurança se deu em virtude da incompreensão do conteúdo, da ausência de estudo prévio ou simplesmente por inabilidades socioemocionais que impediram o bom desempenho da comunicação no momento da sua participação.

Ademais, no cotidiano de uma das turmas, era perceptível uma certa subdivisão em "guetos" dentro da própria sala de aula, simbolizada, inclusive, pelo arranjo das cadeiras no espaço. Eventualmente, alguns comentários hostis eram direcionados a outros colegas de sala. Embora não se tenha realizado uma investigação científica adequada para compreensão dos problemas de interação, pela própria natureza dos comentários, supomos que tal comportamento se dava em razão de conflitos gerados pelas diferenças e, naturalmente, pelo desrespeito às diferenças.

\footnotetext{
5 Julgamos essa atividade "complexa" pelo caráter inédito de elaboração de uma resenha crítica comparativa entre gramáticos pelos alunos em questão; e pela mobilização dos processos cognitivos requeridos para o cumprimento dessa atividade, conforme a Taxonomia de Bloom: Recordar, Entender, Aplicar, Analisar e Avaliar. Apenas a subcategoria Criar não foi necessária para o cumprimento dessa atividade.
} 
Por isso mesmo, advogamos em defesa de um uso mais amplo do jogo de tabuleiro ou de qualquer outra metodologia ativa em detrimento do uso exclusivo do "exercício de verificação", por exemplo, primeiro porque as competências e habilidades socioemocionais tradicionalmente não são contempladas na andragogia; e segundo porque não há como identificar problemas de interação com raras implementações ou se o aluno é verdadeiramente ético, colaborativo, criativo, resiliente, etc., sem colocá-lo numa situação de interação em pares ou em grupos. No máximo, teremos uma vaga ideia de seus valores e atitudes a partir do seu discurso.

\section{Considerações finais}

O presente trabalho pretendeu descrever uma experiência de aplicação do jogo de tabuleiro no ensino superior, em dois componentes curriculares do curso de Licenciatura em Letras da Universidade Federal de Campina Grande: Sintaxe Oracional e Sintaxe Interoracional. Teoricamente estruturado na TAD e na pedagogia da autonomia (FREIRE, 1992, 1996), na proposta de ensino por competência (ALLAL, 2004) e na Taxonomia de Bloom, apresentamos as metodologias ativas e, mais especificamente, o jogo de tabuleiro como um potencial recurso didático de operacionalização da dialética freireana e do ensino por competência.

De modo geral, os resultados confirmam a produtividade do jogo no contexto de uma sequência de atividades de uma educação que se pretende libertadora. Nos componentes curriculares Sintaxe Oracional e Interoracional, os resultados da execução do jogo apontam para: a possibilidade de sistematização dos objetos de aprendizagem do domínio cognitivo numa sequência de atividades; a garantia da dialética "teoriaprática" e "professor-aluno" na experiência de implementação; o potencial exploratório das competências e habilidades cognitivas e socioemocionais; o favorecimento da autonomia do aluno.

Ademais, a discussão dos resultados aponta para a possibilidade de um outro "modo de fazer" em sala de aula, diferente da educação bancária, sem necessariamente prescindir mudanças substanciais no cenário educativo. A respeito desse tópico, defendemos a implementação da educação libertadora freireana, combinada com a proposta do ensino por competência. Especificamente quanto ao trabalho docente, a implementação dessas propostas implica uma reflexão/reconfiguração teóricometodológica, implica um "educador-educando" no processo de aprendizagem, o que significa um deslocamento do lugar do "professor transmissor de conteúdo" nas metodologias tradicionais para um lugar de colaborador nas metodologias ativas, com uma postura dialógica, inclusiva, favorecendo a construção de significados e, sobretudo, a construção de autonomia daqueles que estão em processo de formação.

Acima de tudo, defendemos a humanização na educação, a partir do amplo desenvolvimento das habilidades socioemocionais, não em atendimento a uma demanda do mercado, mas como alternativa de ampliação da cidadania, do desenvolvimento humano e social sustentável, mirando, sempre, na promoção da consciência ecológica, do respeito à diversidade e, consequentemente, na diminuição dos vários tipos de violência, dos problemas de saúde mental, etc. E, nesse contexto de desenvolvimento das habilidades socioemocionais, as metodologias ativas nos parecem bastante oportunas.

\section{Referências}


ALLAL, L. Aquisição e avaliação das competências em situação escolar. In: DOLZ, J.; OLLAGNER, E. (orgs.). O enigma da competência em educação. Porto Alegre: Artmed, 2004. p.79-96.

ANTUNES, C. Jogos para estimulação das múltiplas inteligências. Petrópolis, RJ: Vozes, 2014.

BACICH, L.; MORAN, J. (orgs.) Metodologias ativas para uma educação inovadora: uma abordagem teórico-prática. Porto Alegre: Penso, 2018.

BERGMANN, J.; SAMS, A. How the Flipped Classroom is radically transforming learning. The Daily Riff, 15 abr. 2012. Learning, Innovation \& tech. Disponível em: http://www.thedailyriff.com/articles/how-the-flipped-classroom-is-radicallytransforming-learning-536.php. Acesso em: 18 jul. 2018.

BLOOM, Benjamim S.; KRATHWOHL, David R.; MASIA, Bertram B. Taxonomia dos objetivos educacionais. v. 1 (Domínio Cognitivo). Porto Alegre: Globo, 1973.

CAMARGO, F.; DAROS, T. A sala de aula inovadora: estratégias pedagógicas para fomentar o aprendizado ativo. Porto Alegre: Penso, 2018.

FREIRE, Paulo. Pedagogia do oprimido. Rio de Janeiro: Paz e Terra, 1992.

FREIRE, Paulo. Pedagogia da autonomia. Rio de Janeiro: Paz e Terra, 1996.

FILATRO, A.; CAVALCANTI, C. C. Metodologias inov-ativas: na educação presencial, a distância e corporativa. São Paulo: Saraiva Educação, 2018.

KRATHWOHL, D. R. A revision of Bloom's taxonomy: an overview. Theory in Practice, 2002, v. 41, n. 4, p. 212-218.

RODRIGUES, C. E, S. de. Habilidades socioemocionais: a OCDE e seu programa de governança educacional global. 37 ${ }^{\mathrm{a}}$ Reunião Nacional da ANPEd - 04 a 08 de outubro de 2015, UFSC - Florianópolis. Disponível em: http://37reuniao.anped.org.br/wpcontent/uploads/2015/02/Trabalho-GT13-4316.pdf. Acesso em: 18 jul. 2018.

SANTOS, Santa Marli Pires dos (org.). O lúdico na formação de professores. 7. ed. Petrópolis, RJ: Vozes, 2007.

SCHMITZ, E. X. da S. (2016). Sala de aula invertida: uma abordagem para combinar metodologias ativas e engajar alunos no processo de ensino-aprendizagem. Dissertação (Mestrado em Tecnologias Educacionais em Rede - Universidade Federal de Santa Maria (UFSM, RS)

Recebido em 08 de março de 2020

Aceito em 31 de maio de 2020 